\title{
Multiple Positive Periodic Solutions for Functional Differential Equations with Impulses and a Parameter
}

\author{
Zhenguo Luo ${ }^{1,2}$ \\ ${ }^{1}$ Department of Mathematics, Hengyang Normal University, Hengyang, Hunan 421008, China \\ ${ }^{2}$ China Department of Mathematics, National University of Defense Technology, Changsha, Hunan 410073, China \\ Correspondence should be addressed to Zhenguo Luo; robert186@163.com
}

Received 19 November 2013; Revised 24 December 2013; Accepted 7 January 2014; Published 26 March 2014

Academic Editor: Yun Kang

Copyright (c) 2014 Zhenguo Luo. This is an open access article distributed under the Creative Commons Attribution License, which permits unrestricted use, distribution, and reproduction in any medium, provided the original work is properly cited.

We apply the Krasnoselskii fixed-point theorem to investigate the existence of multiple positive periodic solutions for a class of impulsive functional differential equations with a parameter; some verifiable sufficient results are established easily. In particular, our results extend and improve some previous results.

\section{Introduction}

It is well known that impulsive differential equations arise naturally from a wide variety of applications such as aircraft control, the inspection processes in operations research, drug administration, and threshold theory in biology. Therefore, the impulsive differential equations represent a more natural framework for the mathematical model of many real world phenomena than differential equations (see [1-7]). In recent years, many researchers have obtained some properties of impulsive differential equations, such as oscillation, asymptotic behavior, stability and existence of solutions (see [8-16]). However, there are a little work discussing the existence of multiple positive periodic solutions for the high-dimensional functional differential equations with impulse and parameters. Motivated by this, in this paper, we mainly consider the following impulsive functional differential equations with a parameter:

$$
\begin{gathered}
x^{\prime}(t)=A(t, x(t)) x(t)+\lambda B(t, x(t)) f\left(t, x_{t}\right), \\
t \in R, \quad t \neq t_{k}, \\
\Delta x\left(t_{k}\right)=I_{k}\left(t_{k}, x\left(t_{k}\right)\right), \quad k \in Z_{+},
\end{gathered}
$$

where $\lambda>0$ is a parameter, $A(t, x(t))=\operatorname{diag}\left[a_{1}(t, x(t))\right.$, $\left.a_{2}(t, x(t)), \ldots, a_{n}(t, x(t))\right], B(t, x(t))=\operatorname{diag}\left[b_{1}(t, x(t))\right.$, $\left.b_{2}(t, x(t)), \ldots, b_{n}(t, x(t))\right], a_{j}, b_{j} \in C\left(R \times R^{+}, R^{+}\right)(j=1, \ldots, n)$ are $\omega$-periodic. $f=\left(f_{1}, \ldots, f_{n}\right)^{T}, f\left(t, x_{t}\right)$ is an operator on
$R \times B C\left(R, R^{n}\right)$ (here $B C\left(R, R^{n}\right)$ denoting the Banach space of bounded continuous operator $\varphi: R \rightarrow R^{n}$ with the norm $\|\varphi\|=\sum_{i+1}^{n} \sup _{\theta \in R}|\varphi(\theta)|$, where $\left.\left.\varphi=\left(\varphi_{1}, \ldots, \varphi_{n}\right)^{T}\right)\right)$; $f_{i}\left(t+\omega, x_{t}\right)=f_{i}\left(t, x_{t}\right)$. If $x \in B C\left(R, R^{n}\right)$, then $x_{t} \in B C\left(R, R^{n}\right)$ for any $t \in R$, where $x_{t}$ is defined by $x_{t}(\theta)=x(t+\theta)$ for $\theta \in R$ and $\Delta x\left(t_{k}\right)=x\left(t_{k}^{+}\right)-x\left(t_{k}\right)$ (here $x\left(t_{k}^{+}\right)$representing the right limit of $x(t)$ at the point $\left.t_{k}\right)$. Consider that $I_{k}=$ $\left(I_{k}^{1}, I_{k}^{2}, \ldots, I_{k}^{n}\right) \in C\left(R_{+}^{n}, R_{-}^{n}\right)$; that is, $x$ changes decreasingly suddenly at times $t_{k} . \omega>0$ is a constant, $Z_{+}=\{1,2,3, \ldots\}$, $R=(-\infty,+\infty), R_{+}=[0,+\infty)$, and $R_{-}=(-\infty, 0]$. We assume that there exists an integer $q>0$ such that $t_{k+q}=t_{k}+\omega$, $I_{k+q}=I_{k}$, where $0<t_{1}<t_{2}<\cdots<t_{q}<\omega$.

It is well known that the functional differential system (1) includes many mathematical ecological models for example:

in the case (a), $B(t, x(t)) \equiv 1, I_{k}\left(t_{k}, x\left(t_{k}\right)\right) \equiv 0$ in [17], Zeng et al. studied the existence of multiple positive periodic solutions of (1) by applying the Krasnoselskii fixed-point theorem.

in the case (b), $A(t, x(t))=A(t), \lambda B(t, x(t)) \equiv$ 1 ; in [18], Zhang et al. established the existence of positive periodic solutions of (1) by using the fixedpoint theorem in cones.

in the case (c), $A(t, x(t))=A(t), B(t, x(t)) \equiv 1$, and $I_{k}\left(t_{k}, x\left(t_{k}\right)\right) \equiv 0$; in [19], Jiang et al. investigated the existence, multiplicity, and nonexistence of positive periodic solutions of (1). 
In this paper, we will study the existence of positive periodic solutions in more cases than the previously mentioned papers and obtain some easily verifiable sufficient criteria. tions:

Throughout the paper, we make the following assump-

$\left(H_{1}\right) a_{i}, b_{i}: R \times R_{+} \rightarrow R_{+}$satisfy Caratheodory conditions; that is, $a_{i}(t, x), b_{i}(t, x)$ are locally Lebesgue measurable in $t$ for each fixed $x$, are continuous in $x$ for each fixed $t$, and are $\omega$-periodic functions in $t$. Moreover, there exist $\omega$-periodic functions $a_{1 i}, a_{2 i}, b_{1 i}$, $b_{2 i}: R \rightarrow R_{+}$which are locally bounded Lebesgue measurable such that $a_{1 i}(t) \leq a_{i}(t, x(t)) \leq a_{2 i}(t)$, $b_{1 i}(t) \leq b_{1 i}(t, x(t)) \leq b_{2 i}(t)$ and $\int_{0}^{\omega} a_{1 i}(t) d t>0$, $\int_{0}^{\omega} b_{1 i}(t) d t>0$;

$\left(H_{2}\right) f\left(t, \varphi_{t}\right) \leq 0$ for all $(t, \varphi) \in R \times B C\left(R, R_{+}^{n}\right)$, and $f_{i}\left(t, \varphi_{t}\right)$ is a continuous function of $t$ for each $\varphi \in B C\left(R, R_{+}^{n}\right)$, $i=1,2, \ldots, n$;

$\left(H_{3}\right)$ for any $L>0$ and $\epsilon>0$, there exists $\delta>0$ such that for $\phi, \psi \in B C\left(R, R_{+}^{n}\right),|\phi| \leq L,|\psi| \leq L$, and $|\phi-\psi|<\delta$ imply that $\left|f_{i}\left(s, \phi_{s}\right)-f_{i}\left(s, \psi_{s}\right)\right|<\epsilon, s \in[0, \omega](i=$ $1,2, \ldots, n)$;

$\left(H_{4}\right)\left\{t_{k}\right\}, k \in Z_{+}$satisfies $0<t_{1}<t_{2}<\cdots<t_{k}<$ $\cdots$ and $\lim _{k \rightarrow+\infty} t_{k}=+\infty ; I_{k}: R \times R_{+} \rightarrow R$, $k \in Z_{+}$, satisfy Caratheodory conditions and are $\omega$ periodic functions in $t$ and, moreover, $I_{k}(t, 0)=0$ for all $k \in Z^{+}$. There exists a positive constant $q$ such that $t_{k+q}=t_{k}+\omega, I_{k+q}\left(t_{k+q}, x\left(t_{k+q}\right)\right)=I_{k}\left(t_{k}, x\left(t_{k}\right)\right), k \in Z_{+}$. Without loss of generality, we can assume that $t_{k} \neq 0$ and $[0, \omega] \cap\left\{t_{k}, k \in Z^{+}\right\}=\left\{t_{1}, t_{2}, \ldots, t_{q}\right\}$.

In addition, the parameters in this paper are assumed to be not identically equal to zero.

Furthermore, we will use the following notation. Let $J \subset$ $R$ denote by $P C\left(J, R^{n}\right)$ the set of operators $\varphi: J \rightarrow R^{n}$ which are continuous for $t \in J, t \neq t_{k}$ and have discontinuities of the first kind at the points $t_{k} \in J\left(k \in Z_{+}\right)$but are continuous from the left at these points. For each $x=\left(x_{1}, x_{2}, \ldots, x_{n}\right)^{T} \in R^{n}$, the norm of $x$ is defined as $|x|=\sum_{i=1}^{n}\left|x_{i}\right|$. The matrix $A>$ $B(A \leq B)$ means that each pair of corresponding elements of $A$ and $B$ satisfies the inequality " $>$ " (" $\leq$ "). In particular, $A$ is called a positive matrix if $A>0$.

The paper is organized as follows. In Section 2, we give some definitions and lemmas to prove the main results of this paper. In Section 3, existence theorems for one or two positive periodic solutions of (1) are established by using the Krasnoselskii fixed-point theorem under some conditions.

\section{Preliminaries}

In this section, we make some preparations for the following sections. For $(t, s) \in R^{2}, 1 \leq i \leq n$, we define

$$
\begin{gathered}
G_{i}(t, s)=\frac{e^{-\int_{t}^{s} a_{i}(\xi, x(\xi))} d \xi}{e^{-\int_{0}^{\omega} a_{i}(\xi, x(\xi))} d \xi-1} \\
G(t, s)=\operatorname{diag}\left[G_{1}(t, s), G_{2}(t, s), \ldots, G_{n}(t, s)\right] .
\end{gathered}
$$

It is clear that $G_{i}(t+\omega, s+\omega)=G_{i}(t, s), \partial G_{i}(t, s) / \partial t=$ $a_{i}(t, x(t)) G_{i}(t, s), G_{i}(t, t+\omega)-G_{i}(t, t)=1$. For all $(t, s) \in R^{2}$ and by $\left(\mathrm{H}_{2}\right)$, we have

$$
\begin{array}{r}
G_{i}(t, s) f_{i}\left(s, \varphi_{s}\right) \geq 0, \quad \text { for any }(t, s) \in R^{2}, \\
\left(s, \varphi_{s}\right) \in R \times B C\left(R, R_{+}^{n}\right) .
\end{array}
$$

In view of $\left(H_{1}\right)$, we also define for $1 \leq i \leq n$ the following:

$$
\begin{gathered}
\alpha_{i}:=\min _{0 \leq t \leq s \leq \omega}\left|G_{i}(t, s)\right|=\frac{e^{-\int_{0}^{\omega} a_{2 i}(\xi, x(\xi)) d \xi}}{1-e^{-\int_{0}^{\omega} a_{2 i}(\xi, x(\xi)) d \xi},} \\
\beta_{i}:=\max _{0 \leq t \leq s \leq \omega}\left|G_{i}(t, s)\right|=\frac{e^{-\int_{0}^{\omega} a_{1 i}(\xi, x(\xi)) d \xi}}{1-e^{-\int_{0}^{\omega} a_{1 i}(\xi, x(\xi)) d \xi},} \\
\alpha=\min _{1 \leq i \leq n} \alpha_{i}, \quad \beta=\max _{1 \leq i \leq n} \beta_{i}, \quad \sigma=\frac{\alpha}{\beta} \in(0,1), \\
B_{i}(t)=\max \left\{\left|b_{1 i}(t)\right|,\left|b_{2 i}(t)\right|\right\}, \\
B_{i}^{\prime}(t)=\min \left\{\left|b_{1 i}(t)\right|,\left|b_{2 i}(t)\right|\right\}, \\
B(t)=\max _{1 \leq i \leq n}\left\{B_{i}(t)\right\}, \quad B^{\prime}(t)=\min _{1 \leq i \leq n}\left\{B_{i}^{\prime}(t)\right\} .
\end{gathered}
$$

Let $X=\left\{x=\left(x_{1}(t), x_{2}(t), \ldots, x_{n}(t)\right)^{T} \in P C\left(R, R^{n}\right)\right.$ $x(t+\omega)=x(t)\}$ with the norm $\|x\|=\sum_{i=1}^{n}\left|x_{i}\right|_{0},\left|x_{i}\right|_{0}=$ $\sup _{t \in[0, \omega]}\left|x_{i}(t)\right|$. It is easy to verify that $(X,\|\cdot\|)$ is a Banach space. Define $E$ as a cone in $X$ by

$$
\begin{gathered}
E=\left\{x=\left(x_{1}(t), x_{2}(t), \ldots, x_{n}(t)\right)^{T} \in X: x_{i}(t)\right. \\
\left.\geq \sigma\left\|x_{i}\right\|_{0}, \quad t \in[0, \omega]\right\} .
\end{gathered}
$$

We easily verify that $E$ is a cone in $X$. We define an operator $T: X \rightarrow X$ as follows:

$$
(T x)(t)=\left(\left(T_{1} x\right)(t),\left(T_{2} x\right)(t), \ldots,\left(T_{n} x\right)(t)\right)^{T},
$$

where

$$
\begin{aligned}
\left(T_{i} x\right)(t)= & \lambda \int_{t}^{t+\omega} G_{i}(t, s) b_{i}(s, x(s)) f_{i}\left(s, x_{s}\right) d s \\
& +\sum_{t \leq t_{k}<t+\omega} G_{i}\left(t, t_{k}\right) I_{k}^{i}\left(t_{k}, x\left(t_{k}\right)\right) .
\end{aligned}
$$

The proofs of the main results in this paper are based on an application of the Krasnoselskii fixed-point theorem in cones. To make use of the fixed-point theorem in cones, firstly, we need to introduce some definitions and lemmas.

Definition 1 (see [20]). A function $x: R \rightarrow(0,+\infty)$ is said to be a positive solution of (1), if the following conditions are satisfied:

(a) $x(t)$ is absolutely continuous on each $\left(t_{k}, t_{k+1}\right)$;

(b) for each $k \in Z_{+}, x\left(t_{k}^{+}\right)$and $x\left(t_{k}^{-}\right)$exist, and $x\left(t_{k}^{-}\right)=$ $x\left(t_{k}\right)$

(c) $x(t)$ satisfies the first equation of (1) for almost everywhere in $R$ and $x\left(t_{k}\right)$ satisfies the second equation of (1) at impulsive point $t_{k}, k \in Z_{+}$. 
Definition 2 (see [21]). Let $X$ be a real Banach space; $E$ is a cone of $X$. The semiorder induced by the cone $E$ is denoted by " $\leq$ "; that is, $x \leq y$ if and only if $y-x \in P$ for any $x, y \in E$.

Secondly, let us introduce the Krasnoselskii point theorem in cones which will be used in this paper.

Lemma 3 (for the Krasnoselskii fixed-point theorem; see [22$24])$. Let $E$ be a cone in a real Banach space $X$. Assume that $\Omega_{1}$ and $\Omega_{2}$ are open subsets of $X$ with $0 \in \Omega_{1} \subset \overline{\Omega_{1}} \subset \Omega_{2}$, where $\Omega_{i}=\left\{x \in X:\|x\|<r_{i}\right\}(i=1,2)$. Let $T: E \cap\left(\Omega_{2} \backslash \overline{\Omega_{1}}\right) \rightarrow E$ be a completely continuous operator and satisfy either

(1) $\|T x\| \geq\|x\|$, for any $x \in E \cap \partial \Omega_{1}$ and $\|T x\| \leq\|x\|$, for any $x \in E \cap \partial \Omega_{2}$, or

(2) $\|T x\| \leq\|x\|$, for any $x \in E \cap \partial \Omega_{1}$ and $\|T x\| \geq\|x\|$, for any $x \in E \cap \partial \Omega_{2}$.

Then $T$ has a fixed point in $E \cap\left(\Omega_{2} \backslash \overline{\Omega_{1}}\right)$.

Lemma 4 (see [25]). Assume that $f(t)$ and $g(t)$ are continuous nonnegative functions defined on the interval $[\alpha, \beta]$; then there exists $\xi \in[\alpha, \beta]$ such that

$$
\int_{\alpha}^{\beta} f(t) g(t) d t=f(\xi) \int_{\alpha}^{\beta} g(t) d t
$$

Lemma 5. Assume that $\left(H_{1}\right)-\left(H_{4}\right)$ hold. The existence of positive w-periodic solution of (1) is equivalent to that of nonzero fixed point of $T$ in $E$.

Proof. Assume that $x=\left(x_{1}(t), x_{2}(t), \ldots, x_{n}(t)\right)^{T} \in X$ is a periodic solution of (1). Then, we have

$$
\begin{aligned}
& {\left[x_{i}(t) e^{-\int_{0}^{t} a_{i}(s, x(s)) d s}\right]^{\prime}} \\
& =\lambda e^{-\int_{0}^{t} a_{i}(s, x(s)) d s} b_{i}(t, x(t)) f_{i}\left(t, x_{t}\right), \\
& t \neq t_{k}, \quad i=1,2, \ldots, n .
\end{aligned}
$$

Integrating the above equation over $[t, t+\omega]$, we can have

$$
\begin{aligned}
\left.x_{i}(u) e^{-\int_{0}^{u} a_{i}(s, x(s)) d s}\right|_{t} ^{t_{m_{1}}+n \omega} \\
\quad+\left.x_{i}(u) e^{-\int_{0}^{u} a_{i}(s, x(s)) d s}\right|_{t_{m_{1}}+n \omega} ^{t_{m_{2}}+n \omega}+\cdots \\
\quad+\left.x_{i}(u) e^{-\int_{0}^{u} a_{i}(s, x(s)) d s}\right|_{t_{m_{q}}+n \omega} ^{t+\omega} \\
=\lambda \int_{t}^{t+\omega} e^{-\int_{0}^{u} a_{i}(s, x(s)) d s} b_{i}(u, x(u)) f_{i}\left(u, x_{u}\right) d u,
\end{aligned}
$$

where $t_{m_{k}}+n \omega \in(t, t+\omega), m_{k} \in\{1,2, \ldots, q\}, k=1,2, \ldots, q$, and $n \in Z_{+}$. Therefore,

$$
\begin{aligned}
x_{i}(t) & e^{-\int_{0}^{t} a_{i}(s, x(s)) d s}\left[e^{-\int_{t}^{t+\omega} a_{i}(s, x(s)) d s}-1\right] \\
& -\sum_{t \leq t_{k}<t+\omega} \Delta x_{i}\left(t_{m_{k}}\right) e^{-\int_{0}^{t_{m_{k}}+n \omega} a_{i}(s, x(s)) d s} \\
= & \lambda \int_{t}^{t+\omega} e^{-\int_{0}^{u} a_{i}(s, x(s)) d s} b_{i}(u, x(u)) f_{i}\left(u, x_{u}\right) d u,
\end{aligned}
$$

which can be transformed into

$$
\begin{aligned}
x_{i}(t)= & \lambda \int_{t}^{t+\omega} G_{i}(t, s) b_{i}(s, x(s)) f_{i}\left(s, x_{s}\right) d s \\
& +\sum_{t \leq t_{k}<t+\omega} G_{i}\left(t, t_{k}\right) I_{k}^{i}\left(t_{k}, x\left(t_{k}\right)\right)=\left(T_{i} x\right)(t) .
\end{aligned}
$$

Thus, $x_{i}$ is a periodic solution for (7).

If $x=\left(x_{1}(t), x_{2}(t), \ldots, x_{n}(t)\right)^{T} \in E$ and $T x=$ $\left(T_{1} x, T_{2} x, \ldots, T_{n} x\right)^{T}=x$ with $x \neq 0$, then, for any $t=t_{k}$ we can get the derivation of (7) about $t$,

$$
\begin{aligned}
\left(T_{i} x\right)^{\prime}(t)=\frac{d}{d t}\left[\lambda \int_{t}^{t+\omega} G_{i}(t, s) b_{i}(s, x(s)) f_{i}\left(s, x_{s}\right) d s\right] \\
=\lambda\left[G_{i}(t, t+\omega) b_{i}(t+\omega, x(t+\omega))\right. \\
\quad \times f_{i}\left(t+\omega, x_{t+\omega}\right)-G_{i}(t, t) \\
\left.\quad \times b_{i}(t, x(t)) f_{i}\left(t, x_{t}\right)\right]+a_{i}(t, x(t)) x_{i}(t) \\
=a_{i}(t, x(t)) x_{i}(t)+\lambda b_{i}(t, x(t)) f_{i}\left(t, x_{t}\right)=x_{i}^{\prime}(t) .
\end{aligned}
$$

For any $t=t_{j}, j \in Z_{+}$, we have from (7) that

$$
\begin{aligned}
x_{i}\left(t_{j}^{+}\right)- & x_{i}\left(t_{j}\right) \\
= & \lambda \int_{t_{j}}^{t_{j}+\omega}\left[G_{i}\left(t_{j}^{+}, s\right)-G_{i}\left(t_{j}, s\right)\right] \\
& \times b_{i}(s, x(s)) f_{i}\left(s, x_{s}\right) d s \\
& +\sum_{t_{j}^{+} \leq t_{k}<t_{j}+\omega} G_{i}\left(t_{j}^{+}, t_{k}\right) I_{k}^{i}\left(t_{k}, x\left(t_{k}\right)\right) \\
& -\sum_{t_{j} \leq t_{k}<t_{j}+\omega} G_{i}\left(t_{j}, t_{k}\right) I_{k}^{i}\left(t_{k}, x\left(t_{k}\right)\right) \\
= & I_{k}^{i}\left(t_{k}, x\left(t_{k}\right)\right) .
\end{aligned}
$$

Hence $x(t)=\left(x_{1}(t), x_{2}(t), \ldots, x_{n}(t)\right)^{T}$ is a positive $\omega$-periodic solution of (1). Thus we complete the proof of Lemma 5.

Lemma 6. Assume that $\left(H_{1}\right)-\left(H_{4}\right)$ hold. Then $T: E \rightarrow E$ is well defined. 
Proof. From (7), it is easy to verify that $(T x)(t)$ is continuous in $\left(t_{k}, t_{k+1}\right),(T x)\left(t_{k}^{+}\right)$and $(T x)\left(t_{k}^{-}\right)$exist, and $(T x)\left(t_{k}^{-}\right)=$ $(T x)\left(t_{k}\right)$ for each $k \in Z_{+}$. Moreover, for any $x \in E$,

$$
\begin{aligned}
(T x)(t+\omega)= & \lambda \int_{t+\omega}^{t+2 \omega} G(t+\omega, s) b(s, x(s)) f\left(s, x_{s}\right) d s \\
& +\sum_{t+\omega \leq t_{k}<t+2 \omega} G\left(t+\omega, t_{k}\right) I_{k}\left(t_{k}, x\left(t_{k}\right)\right) \\
= & \lambda \int_{t}^{t+\omega} G(t+\omega, u+\omega) \\
& +\sum_{t \leq t_{k}<t+\omega} G\left(t, t_{k}\right) I_{k}\left(t_{k}, x\left(t_{k}\right)\right) \\
= & \lambda \int_{t}^{t+\omega} G(t, s) b(s, x(s)) f\left(s, x_{s}\right) d s \\
& +\sum_{t \leq t_{k}<t+\omega} G\left(t, t_{k}\right) I_{k}\left(t_{k}, x\left(t_{k}\right)\right)=(T x)(t) .
\end{aligned}
$$

Therefore, $(T x) \in X$. From (7), we have

$$
\begin{gathered}
\left|T_{i} x\right|_{0} \leq \beta_{i}\left[\lambda \int_{0}^{\omega}\left|b_{i}(s, x(s)) f_{i}\left(s, x_{s}\right)\right| d s\right. \\
\left.+\sum_{t \leq t_{k}<t+\omega} I_{k}^{i}\left(t_{k}, x\left(t_{k}\right)\right)\right] .
\end{gathered}
$$

Noticing that $G_{i}(t, s) f_{i}\left(s, x_{s}\right) \geq 0$, we obtain

$$
\begin{gathered}
\left(T_{i} x\right)(t) \geq \alpha_{i}\left[\lambda \int_{0}^{\omega}\left|b_{i}(s, x(s)) f_{i}\left(s, x_{s}\right)\right| d s\right. \\
\left.+\sum_{t \leq t_{k}<t+\omega} I_{k}^{i}\left(t_{k}, x\left(t_{k}\right)\right)\right] \\
\geq \frac{\alpha_{i}}{\beta_{i}}\left|T_{i} x\right|_{0} \geq \sigma\left|T^{i} x\right|_{0} .
\end{gathered}
$$

Therefore, $T x \in E$. This completes the proof of Lemma 6 .

Lemma 7. Assume that $\left(H_{1}\right)-\left(H_{4}\right)$ hold. Then $T: E \rightarrow E$ is completely continuous.

Proof. We first show that $T$ is continuous. By $\left(H_{3}\right)-\left(H_{4}\right), f$ and $I_{k}$ are continuous in $x$; it follows that, for any $\epsilon>0$, let $\delta>0$ be small enough to satisfy that, if $x, y \in E$, with $|x-y|<$ $\delta$,

$$
\begin{gathered}
\left|f\left(s, x_{s}\right)-f\left(s, y_{s}\right)\right|<\frac{\epsilon}{2 \bar{B} \lambda \beta \omega}, \quad s \in R \\
\left|I_{k}\left(t_{k}, x\left(t_{k}\right)\right)-I_{k}\left(t_{k}, y\left(t_{k}\right)\right)\right|<\frac{\epsilon}{2 \beta q}, \quad k \in Z_{+} .
\end{gathered}
$$

Therefore,

$$
\begin{aligned}
& \|(T x)(t)-(T y)(t)\| \\
& =\sum_{i=1}^{n}\left|T_{i} x-T_{i} y\right|_{0} \\
& \leq \beta \sum_{i=1}^{n} \lambda \int_{t}^{t+\omega} \mid b_{i}(s, x(s)) f_{i}\left(s, x_{s}\right) \\
& +\beta \sum_{i=1}^{n} \sum_{t \leq t_{k}<t+\omega} \mid I_{k}^{i}\left(t_{k}, x\left(t_{k}\right)\right) \\
& <\beta \lambda \bar{B} \omega \frac{\epsilon}{2 \bar{B} \lambda \beta \omega}+\beta q \frac{\epsilon}{2 \beta q}=\epsilon,
\end{aligned}
$$

which implies that $T$ is continuous on $E$.

Next we show that $T$ maps a bounded set into a bounded set. Indeed, let $C \subset E$ be a bounded set. For any $t \in R$ and $x \in C$, by (7), we have

$$
\begin{aligned}
\|(T x)(t)\|= & \sum_{i=1}^{n}\left|T_{i} x\right|_{0} \\
\leq \beta & {\left[\lambda \sum_{i=1}^{n} \int_{t}^{t+\omega}\left|b_{i}(s, x(s)) f_{i}\left(s, x_{s}\right)\right| d s\right.} \\
& \left.+\sum_{i=1}^{n} \sum_{t \leq t_{k}<t+\omega}\left|I_{k}^{i}\left(t_{k}, x\left(t_{k}\right)\right)\right|\right] \\
=\beta & {\left[\int_{0}^{\omega} b_{2 i}(s) f\left(s, x_{s}\right) d s\right.} \\
& \left.+\sum_{t \leq t_{k}<t+\omega}\left|I_{k}\left(t_{k}, x\left(t_{k}\right)\right)\right|\right]
\end{aligned}
$$

Since $C$ is bounded, in view of the continuity of $T$, it follows from (19) that $T x$ is bounded and $\{T x: x \in C\}$ is uniformly bounded. Finally, we show that the family of functions $\{T x$ : $x \in C\}$ is equicontinuous on $[0, \omega]$. Let $\theta_{1}, \theta_{2} \in[0, \omega]$ with $\theta_{1}<\theta_{2}$. From (7), for any $x \in C$, we have

$$
\begin{aligned}
\left\|(T x)\left(\theta_{2}\right)-(T x)\left(\theta_{1}\right)\right\| \\
\leq \lambda \sum_{i=1}^{n}\left[\int_{\theta_{1}}^{\theta_{2}}\left(G_{i}\left(\theta_{2}, s\right)-G_{i}\left(\theta_{1}, s\right)\right)\right. \\
\quad \times b_{i}(s, x(s)) f_{i}\left(s, x_{s}\right) d s \\
+\int_{\theta_{2}}^{\theta_{1}+\omega}\left(G_{i}\left(\theta_{2}, s\right)-G_{i}\left(\theta_{1}, s\right)\right)
\end{aligned}
$$




$$
\begin{gathered}
\times b_{i}(s, x(s)) f_{i}\left(s, x_{s}\right) d s \\
+\sum_{\theta_{1} \leq t_{k}<\theta_{2}}\left(G_{i}\left(\theta_{2}, t_{k}\right)-G_{i}\left(\theta_{1}, t_{k}\right)\right) \\
\quad \times\left|I_{k}^{i}\left(t_{k}, x\left(t_{k}\right)\right)\right| \\
+\sum_{\theta_{2} \leq t_{k}<\theta_{1}+\omega}\left(G_{i}\left(\theta_{2}, t_{k}\right)-G_{i}\left(\theta_{1}, t_{k}\right)\right) \\
\left.\quad \times\left|I_{k}^{i}\left(t_{k}, x\left(t_{k}\right)\right)\right|\right] .
\end{gathered}
$$

Since for $x \in C, t \in[0, \omega], 0 \leq k \leq q, b_{i}(t, x(t))$, $f_{i}\left(t, x\left(t-\tau_{1}(t, x(t))\right), \ldots, x\left(t-\tau_{m}(t, x(t))\right)\right)$, and $I_{k}^{i}\left(t_{k}, x\left(t_{k}\right)\right)$ are uniformly bounded in $X$; in view of (21), it is easy to see that when $\theta_{2}-\theta_{1}$ tends to zero, $\left|(T x)\left(\theta_{2}\right)-(T x)\left(\theta_{1}\right)\right|$ tends uniformly to zero in $X$. Hence, $\{T x: x \in C\}$ is a family of uniformly bounded and equicontinuous functions on $[0, \omega]$. By Ascoli-Arzelà theorem, the operator $T$ is completely continuous. The proof of Lemma 7 is complete.

For convenience in the following discussion, we introduce the following notations:

$$
\begin{aligned}
& f^{a}=\lim _{x \in P,\|x\| \rightarrow a} \operatorname{mux}_{t \in[0, \omega]} \frac{\int_{0}^{\omega}\left|f\left(t, x_{t}\right)\right| d t}{\|x\|}, \\
& f_{a}=\lim _{x \in P,\|x\| \rightarrow a} \min _{t \in[0, \omega]} \frac{\int_{0}^{\omega}\left|f\left(t, x_{t}\right)\right| d t}{\|x\|}, \\
& \bar{f}_{r}=\max _{0<x \leq r} \max _{t \in[0, \omega]} \frac{\int_{0}^{\omega}\left|f\left(t, x_{t}\right)\right| d t}{\|x\|}, \\
& \underline{f}_{r}=\min _{0<x \leq r} \min _{t \in[0, \omega]} \frac{\int_{0}^{\omega}\left|f\left(t, x_{t}\right)\right| d t}{\|x\|}, \\
& I^{a}=\lim _{x \in P,\|x\| \rightarrow a} \operatorname{mux}_{t \in[0, \omega]} \frac{\sum_{t \leq t_{k}<t+\omega}\left|I_{k}(t, x)\right|}{\|x\|}, \\
& \underline{I}_{r}=\min _{0<x \leq r} \min _{t \in[0, \omega], k \in[1, q]} \frac{\sum_{t \leq t_{k}<t+\omega}\left|I_{k}(t, x)\right|}{\|x\|}, \\
& \bar{I}_{r}=\max _{0<x \leq r,\|x\| \rightarrow a} \min _{t \in[0, \omega]} \frac{\sum_{t \leq t_{k}<t+\omega}\left|I_{k}(t, x)\right|}{\|x\|}, \\
& \max _{t \in[0, \omega], k \in[1, q]} \frac{\sum_{t \leq t_{k}<t+\omega}\left|I_{k}(t, x)\right|}{\|x\|},
\end{aligned}
$$

where $a$ denotes either 0 or $\infty, r$ denotes a positive number, and $\|x\|=\max \left\{\left|x_{1}\right|,\left|x_{2}\right|, \ldots,\left|x_{m}\right|\right\}$.

\section{Main Results}

Our main results of this paper are as follows.
Theorem 8. Assume that $\left(H_{1}\right)-\left(H_{4}\right)$ and the following conditions:

$$
\begin{aligned}
& \left(H_{5}\right) \alpha \sigma\left(\lambda B^{\prime}(\xi) \underline{f}_{r}+\underline{I}_{r}\right)>1, \xi \in[0, \omega] \\
& \left(H_{6}\right) f^{0}=I^{0}=f^{\infty}=I^{\infty}=0
\end{aligned}
$$

hold. Then (1) has two positive $\omega$-periodic solutions.

Proof. First, we define $\Omega_{r}=\{x \in X:\|x\|<r\}$; then $\Omega_{r}$ is an open subset of $X$. From (7), $\left(H_{5}\right)$, and Lemma 4, for any $x \in E \cap \partial \Omega_{r}$, we have

$$
\begin{aligned}
\|(T x)(t)\|= & \sum_{i=1}^{n}\left|T_{i} x\right|_{0} \\
= & \sum_{i=1}^{n}\left[\lambda \int_{t}^{t+\omega}\left|G_{i}(t, s) b_{i}(s, x(s)) f_{i}\left(s, x_{s}\right)\right| d s\right. \\
& \left.+\sum_{t \leq t_{k}<t+\omega}\left|G_{i}\left(t, t_{k}\right) I_{k}^{i}\left(t_{k}, x\left(t_{k}\right)\right)\right|\right] \\
\geq & \lambda B^{\prime}(\xi) \sum_{i=1}^{n} \int_{t}^{t+\omega}\left|G_{i}(t, s) f_{i}\left(s, x_{s}\right)\right| d s \\
& +\sum_{i=1}^{n} \sum_{t \leq t_{k}<t+\omega}\left|G_{i}\left(t, t_{k}\right) I_{k}^{i}\left(t_{k}, x\left(t_{k}\right)\right)\right| \\
= & {\left[\lambda B^{\prime}(\xi) \int_{0}^{\omega}\left|f\left(s, x_{s}\right)\right| d s\right.} \\
& \left.+\sum_{t \leq t_{k}<t+\omega}\left|I_{k}\left(t_{k}, x\left(t_{k}\right)\right)\right|\right] \\
& \alpha\left(\lambda B^{\prime}(\xi) \underline{f}_{r}+\underline{I}_{r}\right)\|x\|>\|x\| .
\end{aligned}
$$

This yields

$$
\|(T x)(t)\|>\|x\|, \quad \text { for any } x \in E \cap \partial \Omega_{r} .
$$

On the other hand, if $f^{0}=I^{0}=0$ holds, then we can choose $0<r_{1}<r$, such that $\int_{0}^{\omega}\left|f\left(t, x_{t}\right)\right| d t \leq \epsilon\|x\|$ and $\sum_{t \leq t_{k}<t+\omega}\left|I_{k}\left(t_{k}, x\left(t_{k}\right)\right)\right| \leq \epsilon\|x\|$ for $x \in\left[0, r_{1}\right], t \in[0, \omega]$, and $1 \leq k<q$, where constant $\epsilon>0$ satisfies $\epsilon \beta(\lambda B(\xi)+1) \leq 1$. By (7) and Lemma 4, we can obtain

$$
\begin{aligned}
(T x)(t)= & \sum_{i=1}^{n}\left(T_{i} x\right) \\
=\sum_{i=1}^{n}\left[\lambda \int_{t}^{t+\omega} G_{i}(t, s) b_{i}(s, x(s)) f_{i}\left(s, x_{s}\right) d s\right. & \\
& \left.\quad+\sum_{t \leq t_{k}<t+\omega} G_{i}\left(t, t_{k}\right) I_{k}^{i}\left(t_{k}, x\left(t_{k}\right)\right)\right]
\end{aligned}
$$




$$
\begin{aligned}
& \leq \lambda B(\xi) \sum_{i=1}^{n} \int_{t}^{t+\omega}\left|G_{i}(t, s) f_{i}\left(s, x_{s}\right)\right| d s \\
& +\sum_{i=1}^{n} \sum_{t \leq t_{k}<t+\omega}\left|G_{i}\left(t, t_{k}\right) I_{k}^{i}\left(t_{k}, x\left(t_{k}\right)\right)\right| \\
& =\beta\left[\lambda B(\xi) \int_{0}^{\omega}\left|f\left(s, x_{s}\right)\right| d s\right. \\
& \left.\quad+\sum_{t \leq t_{k}<t+\omega}\left|I_{k}\left(t_{k}, x\left(t_{k}\right)\right)\right|\right] \\
& \leq \epsilon \beta(\lambda B(\xi)+1)\|x\| \leq\|x\| .
\end{aligned}
$$

This yields

$$
\|(T x)(t)\| \leq\|x\|, \quad \text { for any } x \in E \cap \partial \Omega_{r_{1}} .
$$

In view of (24) and (26), by Lemma 3, it follows that $T$ has a fixed point $x_{1} \in E \cap\left(\Omega_{r} \backslash \overline{\Omega_{r 1}}\right)$ with $r_{1}<\left\|x_{1}\right\|<r$, which is a positive $\omega$-periodic solution of (1).

Likewise, if $f^{\infty}=I^{\infty}=0$ holds, then there is $N>0$ such that $\int_{0}^{\omega}\left|f\left(t, x_{t}\right)\right| d t \leq \epsilon\|x\|$ and $\sum_{t \leq t_{k}<t+\omega}\left|I_{k}\left(t_{k}, x\left(t_{k}\right)\right)\right| \leq \epsilon\|x\|$ for $x \geq N, t \in[0, \omega]$, and $1 \leq k<q$, where constant $\epsilon>0$ satisfies $\epsilon \beta(\lambda B(\xi)+1) \leq 1$. Let $r_{2}=\max \{2 r, N / \sigma\}$ and it follows that $x(t) \geq \sigma\|x\|>N$ for $x \in \Omega_{r_{2}}, t \in[0, \omega]$, and $0<k<q$. Thus

$$
\begin{aligned}
& \int_{0}^{\omega}\left|f\left(t, x_{t}\right)\right| d t \leq \epsilon\|x\| ; \\
& \sum_{t \leq t_{k}<t+\omega}\left|I_{k}\left(t_{k}, x\left(t_{k}\right)\right)\right| \leq \epsilon\|x\|,
\end{aligned}
$$

for $x \in \Omega_{r_{2}}, t \in[0, \omega], 1 \leq k<q$.

By (7) and Lemma 4, we have

$$
(T x)(t) \leq \epsilon \beta(\lambda B(\xi)+1)\|x\| \leq\|x\| ;
$$

this yields

$$
\|(T x)(t)\| \leq\|x\|, \quad \text { for any }, x \in E \cap \partial \Omega_{r_{2}} .
$$

In view of (24) and (29), by Lemma 3, it follows that $T$ has a fixed point $x_{2} \in E \cap\left(\Omega_{r_{2}} \backslash \overline{\Omega_{r}}\right)$ with $r<\left\|x_{2}\right\|<r_{2}$, which is a positive $\omega$-periodic solution of (1). Therefore (1) has at least two positive periodic solutions; that is, $r_{1}<\left\|x_{1}\right\|<r<$ $\left\|x_{2}\right\|<r_{2}$. This proves Theorem 8 .

Remark 9. Assume that $\left(H_{1}\right)-\left(H_{4}\right)$ and the following conditions:

$$
\begin{aligned}
& \left(H_{5}\right) \alpha \sigma\left(\lambda B^{\prime}(\xi) \underline{f}_{r}+\underline{I}_{r}\right)>1 ; \\
& \left(H_{7}\right) f^{0}=I^{0}=0, \text { or } f^{\infty}=I^{\infty}=0
\end{aligned}
$$

hold. Then (1) has a positive $\omega$-periodic solution.
Corollary 10. Assume that $\left(H_{1}\right)-\left(H_{3}\right)$ and $\lambda>1 / \alpha \sigma B^{\prime}(\xi) \underline{f}$ hold.

$\left(H_{6}\right)$ is satisfied; then (1) has two positive $\omega$-periodic solutions;

$\left(\mathrm{H}_{7}\right)$ is satisfied; then (1) has a positive $\omega$-periodic solution.

Theorem 11. Assume that $\left(H_{1}\right)-\left(H_{4}\right)$ and the following conditions:

$$
\begin{aligned}
& \left(H_{8}\right) \beta\left(\lambda B(\xi) \bar{f}_{r}+\bar{I}_{r}\right)<1 ; \\
& \left(H_{9}\right) f_{0}=I_{0}=f_{\infty}=I_{\infty}=\infty
\end{aligned}
$$

hold. Then (1) has two positive w-periodic solutions.

Proof. We define $\Omega_{r}=\{x \in X:\|x\|<r\}$, for a positive number $r$. Then $\Omega_{r}$ is an open subset of $X$ and $0 \in \Omega_{r}$. By (7), $\left(H_{8}\right)$, and Lemma 4 , for any $x \in E \cap \partial \Omega_{r}$, we have

$$
\begin{aligned}
\|(T x)(t)\|= & \sum_{i=1}^{n}\left|T_{i} x\right|_{0} \\
= & \sum_{i=1}^{n}\left[\lambda \int_{t}^{t+\omega}\left|G_{i}(t, s) b_{i}(s, x(s)) f_{i}\left(s, x_{s}\right)\right| d s\right. \\
& \left.+\sum_{t \leq t_{k}<t+\omega}\left|G_{i}\left(t, t_{k}\right) I_{k}^{i}\left(t_{k}, x\left(t_{k}\right)\right)\right|\right] \\
\leq & \lambda B(\xi) \sum_{i=1}^{n} \int_{t}^{t+\omega}\left|G_{i}(t, s) f_{i}\left(s, x_{s}\right)\right| d s \\
& +\sum_{i=1}^{n} \sum_{t \leq t_{k}<t+\omega}\left|G_{i}\left(t, t_{k}\right) I_{k}^{i}\left(t_{k}, x\left(t_{k}\right)\right)\right| \\
= & {\left[\begin{array}{l}
\lambda B(\xi) \int_{0}^{\omega}\left|f\left(s, x_{s}\right)\right| d s \\
\leq
\end{array}\right.} \\
& \left.+\sum_{t \leq t_{k}<t+\omega}\left|I_{k}\left(t_{k}, x\left(t_{k}\right)\right)\right|\right] \\
& {\left[B(\xi) \bar{f}_{r}+\bar{I}_{r}\right)\|x\|<\|x\| . }
\end{aligned}
$$

This implies that for any $x \in E \cap \partial \Omega_{r}$

$$
\|(T x)(t)\|<\|x\| .
$$

On the one hand, since $f_{0}=I_{0}=\infty$, there exists $0<r_{1}<r$ and small enough $0<\epsilon$ satisfies $\alpha \delta\left[\lambda B^{\prime}(\xi)\left(f_{0}-\epsilon\right)+\left(I_{0}-\epsilon\right)\right]>$ 1 such that, for any $x$ with $\|x\| \in\left[0, r_{1}\right]$,

$$
\begin{gathered}
\int_{0}^{\omega}\left|f\left(t, x_{t}\right)\right| d t \geq\left(f_{0}-\varepsilon\right)\|x\| ; \\
\sum_{t \leq t_{k}<t+\omega}\left|I_{k}\left(t_{k}, x\left(t_{k}\right)\right)\right| \geq\left(I_{0}-\varepsilon\right)\|x\| .
\end{gathered}
$$


Define $\Omega_{r_{2}}=\left\{x \in X:\|x\|<r_{2}\right\}$; then $\Omega_{r_{1}}$ is an open subset of $X$. For any $x \in E \cap \partial \Omega_{r_{1}}$, by (7) and Lemma 4 , we have

$$
\begin{aligned}
&\|(T x)(t)\|= \sum_{i=1}^{n}\left\|\left(T_{i} x\right)\right\|_{0} \\
&= \sum_{i=1}^{n}\left[\lambda \int_{t}^{t+\omega}\left|G_{i}(t, s) b_{i}(s, x(s)) f_{i}\left(s, x_{s}\right)\right| d s\right. \\
&\left.+\sum_{t \leq t_{k}<t+\omega}\left|G_{i}\left(t, t_{k}\right) I_{k}^{i}\left(t_{k}, x\left(t_{k}\right)\right)\right|\right] \\
& \geq \lambda B^{\prime}(\xi) \sum_{i=1}^{n} \int_{t}^{t+\omega}\left|G_{i}(t, s) f_{i}\left(s, x_{s}\right)\right| d s \\
&+\sum_{i=1}^{n} \sum_{t \leq t_{k}<t+\omega}\left|G_{i}\left(t, t_{k}\right) I_{k}^{i}\left(t_{k}, x\left(t_{k}\right)\right)\right| \\
&= {\left[\lambda B^{\prime}(\xi) \int_{0}^{\omega}\left|f\left(s, x_{s}\right)\right| d s\right.} \\
&\left.+\sum_{t \leq t_{k}<t+\omega}\left|I_{k}\left(t_{k}, x\left(t_{k}\right)\right)\right|\right] \\
& \geq \delta\left[\lambda B^{\prime}(\xi)\left(f_{0}-\epsilon\right)+\left(I_{0}-\epsilon\right)\right]\|x\| \geq\|x\| .
\end{aligned}
$$

This yields

$$
\|(T x)(t)\| \geq\|x\|, \quad \text { for any } x \in E \cap \partial \Omega_{r_{1}} .
$$

In view of (31) and (34), by Lemma 3, it follows that $T$ has a fixed point $x_{1} \in E \cap\left(\Omega_{r} \backslash \overline{\Omega_{r 1}}\right)$ with $r_{1}<\left\|x_{1}\right\|<r$, which is a positive $\omega$-periodic solution of (1). On the other hand, if $f_{\infty}=I_{\infty}=\infty$, we can find small enough $0<\epsilon$ that satisfies $\alpha \delta\left[\lambda B^{\prime}(\xi)\left(f_{\infty}-\epsilon\right)+\left(I_{\infty}-\epsilon\right)\right]>1$ and large enough $\eta>r>0$, such that $\|x\| \geq \eta$,

$$
\begin{gathered}
\int_{0}^{\omega}\left|f\left(t, x_{t}\right)\right| d t \geq\left(f_{\infty}-\epsilon\right)\|x\| ; \\
\sum_{t \leq t_{k}<t+\omega}\left|I_{k}\left(t_{k}, x\left(t_{k}\right)\right)\right| \geq\left(I_{\infty}-\epsilon\right)\|x\| .
\end{gathered}
$$

Define $r_{2}=\eta / \sigma>r$ and $\Omega_{r_{2}}=\left\{x \in X:\|x\|<r_{2}\right\}$; then $\Omega_{r_{2}}$ is an open subset of $X$. For any $x \in E \cap \partial \Omega_{r_{2}}$, from (7) and Lemma 3, we have

$$
\begin{aligned}
\|(T x)(t)\|= & \sum_{i=1}^{n}\left\|\left(T_{i} x\right)\right\|_{0} \\
=\sum_{i=1}^{n}\left[\lambda \int_{t}^{t+\omega}\left|G_{i}(t, s) b_{i}(s, x(s)) f_{i}\left(s, x_{s}\right)\right| d s\right. & \\
& \left.\quad+\sum_{t \leq t_{k}<t+\omega}\left|G_{i}\left(t, t_{k}\right) I_{k}^{i}\left(t_{k}, x\left(t_{k}\right)\right)\right|\right]
\end{aligned}
$$

$$
\begin{aligned}
& \geq \lambda B^{\prime}(\xi) \sum_{i=1}^{n} \int_{t}^{t+\omega}\left|G_{i}(t, s) f_{i}\left(s, x_{s}\right)\right| d s \\
& +\sum_{i=1}^{n} \sum_{t \leq t_{k}<t+\omega}\left|G_{i}\left(t, t_{k}\right) I_{k}^{i}\left(t_{k}, x\left(t_{k}\right)\right)\right| \\
& =\alpha\left[\lambda B^{\prime}(\xi) \int_{0}^{\omega}\left|f\left(s, x_{s}\right)\right| d s\right. \\
& \left.\quad+\sum_{t \leq t_{k}<t+\omega}\left|I_{k}\left(t_{k}, x\left(t_{k}\right)\right)\right|\right] \\
& \geq \alpha \delta\left[\lambda B^{\prime}(\xi)\left(f_{\infty}-\epsilon\right)+\left(I_{\infty}-\epsilon\right)\right]\|x\| \geq\|x\| .
\end{aligned}
$$

This yields

$$
\|(T x)(t)\| \geq\|x\|, \quad \text { for any } x \in E \cap \partial \Omega_{r_{2}} .
$$

In view of (31) and (37), by Lemma 3, it follows that $T$ has a fixed point $x_{2} \in E \cap\left(\Omega_{r_{2}} \backslash \overline{\Omega_{r}}\right)$ with $r<\left\|x_{2}\right\|<r_{2}$, which is a positive $\omega$-periodic solution of (1). Therefore, (1) has at least two positive periodic solutions; that is, $r_{1}<\left\|x_{1}\right\|<r<$ $\left\|x_{2}\right\|<r_{2}$. This proves Theorem 11 .

Remark 12. Assume that $\left(H_{1}\right)-\left(H_{4}\right)$ and the following conditions:

$$
\begin{aligned}
& \left(H_{8}\right) \beta\left(\lambda B(\xi) \bar{f}_{r}+\bar{I}_{r}\right)<1 ; \\
& \left(H_{10}\right) f_{0}=I_{0}=\infty, \text { or } f_{\infty}=I_{\infty}=\infty
\end{aligned}
$$

hold. Then (1) has a positive $\omega$-periodic solution.

Corollary 13. Assume that $\left(H_{1}\right)-\left(H_{3}\right)$ and $\lambda<1 / \beta B(\xi) \bar{f}_{r}$ hold.

$\left(H_{9}\right)$ is satisfied; then (1) has two positive $\omega$-periodic solutions;

$\left(H_{10}\right)$ is satisfied; then (1) has a positive $\omega$-periodic solution.

Theorem 14. Assume that $\left(H_{1}\right)-\left(H_{4}\right)$ and

$$
\begin{aligned}
& \left(H_{11}\right) \beta\left(\lambda B(\xi) f^{0}+I^{0}\right)<1 ; \\
& \left(H_{12}\right) \alpha \sigma\left(\lambda B^{\prime}(\xi) f_{\infty}+I_{\infty}\right)>1
\end{aligned}
$$

hold. Then (1) has a positive $\omega$-periodic solution, where $f^{0}, f_{\infty}$, $I^{0}$, and $I_{\infty}$ are positive constants.

Proof. From $\left(H_{11}\right)$, we can choose $\epsilon>0$ such that $\beta\left(\lambda B(x i)\left(f^{0}+\epsilon\right)+\left(I^{0}+\epsilon\right)\right)<1$. Thus there exists $r>0$ such that, for $x \in[0, r], t \in[0, \omega]$ and $1 \leq k<q$,

$$
\begin{gathered}
\int_{0}^{\omega} f\left(t, x_{t}\right) d t \leq\left(f^{0}+\epsilon\right)\|x\| ; \\
\sum_{t \leq t_{k}<t+\omega} I_{k}\left(t_{k}, x\left(t_{k}\right)\right) \leq\left(I^{0}+\epsilon\right)\|x\|,
\end{gathered}
$$


by $(7),\left(H_{11}\right)$, and Lemma 4 , we have

$$
\begin{aligned}
\|(T x)(t)\|= & \sum_{i=1}^{n}\left|T_{i} x\right|_{0} \\
= & \sum_{i=1}^{n}\left[\lambda \int_{t}^{t+\omega}\left|G_{i}(t, s) b_{i}(s, x(s)) f_{i}\left(s, x_{s}\right)\right|\right. \\
& \left.+\sum_{t \leq t_{k}<t+\omega}\left|G_{i}\left(t, t_{k}\right) I_{k}^{i}\left(t_{k}, x\left(t_{k}\right)\right)\right|\right] \\
\leq & \lambda B(\xi) \sum_{i=1}^{n} \int_{t}^{t+\omega}\left|G_{i}(t, s) f_{i}\left(s, x_{s}\right)\right| d s \\
& +\sum_{i=1}^{n} \sum_{t \leq t_{k}<t+\omega}\left|G_{i}\left(t, t_{k}\right) I_{k}^{i}\left(t_{k}, x\left(t_{k}\right)\right)\right| \\
= & {\left[\lambda B(\xi) \int_{0}^{\omega}\left|f\left(s, x_{s}\right)\right| d s\right.} \\
& \left.+\sum_{t \leq t_{k}<t+\omega}\left|I_{k}\left(t_{k}, x\left(t_{k}\right)\right)\right|\right] \\
\leq & \left.\beta B(\xi)\left(f^{0}+\epsilon\right)+\left(I^{0}+\epsilon\right)\right)\|x\|<\|x\| .
\end{aligned}
$$

This implies that for any $x \in E \cap \partial \Omega_{r}$

$$
\|(T x)(t)\|<\|x\| \text {. }
$$

On the other hand, choose $\varepsilon>0$ such that $f_{\infty}-\epsilon>0$ and $I_{\infty}-\epsilon>0$, and from $\left(H_{12}\right)$, we can obtain

$$
\alpha \sigma\left[\lambda B^{\prime}(\xi)\left(f_{\infty}-\epsilon\right)+\left(I_{\infty}-\epsilon\right)\right]>1 .
$$

It is easy to see that there exists large enough $\eta>r>0$, such that $\|x\| \geq \eta$,

$$
\begin{gathered}
\int_{0}^{\omega}\left|f\left(t, x_{t}\right)\right| d t \geq\left(f_{\infty}-\epsilon\right)\|x\| \\
\sum_{t \leq t_{k}<t+\omega}\left|I_{k}\left(t_{k}, x\left(t_{k}\right)\right)\right| \geq\left(I_{\infty}-\epsilon\right)\|x\| .
\end{gathered}
$$

Define $R=\eta / \sigma>r$ and $\Omega_{R}=\{x \in X:\|x\|<R\}$; then $\Omega_{R}$ is an open subset of $X$. From (7), $\left(H_{12}\right)$, and Lemma 4, for any $x \in E \cap \partial \Omega_{R}$, we have

$$
\begin{aligned}
&\|(T x)(t)\|= \sum_{i=1}^{n}\left|T_{i} x\right|_{0} \\
&=\sum_{i=1}^{n}\left[\lambda \int_{t}^{t+\omega}\left|G_{i}(t, s) b_{i}(s, x(s)) f_{i}\left(s, x_{s}\right)\right| d s\right. \\
&\left.\quad+\sum_{t \leq t_{k}<t+\omega}\left|G_{i}\left(t, t_{k}\right) I_{k}^{i}\left(t_{k}, x\left(t_{k}\right)\right)\right|\right]
\end{aligned}
$$

$$
\begin{aligned}
& \geq \lambda B^{\prime}(\xi) \sum_{i=1}^{n} \int_{t}^{t+\omega}\left|G_{i}(t, s) f_{i}\left(s, x_{s}\right)\right| d s \\
&+\sum_{i=1}^{n} \sum_{t \leq t_{k}<t+\omega}\left|G_{i}\left(t, t_{k}\right) I_{k}^{i}\left(t_{k}, x\left(t_{k}\right)\right)\right| \\
&=\alpha {\left[\lambda B^{\prime}(\xi) \int_{0}^{\omega}\left|f\left(s, x_{s}\right)\right| d s\right.} \\
&\left.+\sum_{t \leq t_{k}<t+\omega}\left|I_{k}\left(t_{k}, x\left(t_{k}\right)\right)\right|\right] \\
& \geq \alpha \sigma\left[\lambda B^{\prime}(\xi)\left(f_{\infty}-\epsilon\right)+\left(I_{\infty}-\epsilon\right)\right]\|x\|>\|x\| .
\end{aligned}
$$

This yields

$$
\|T x\|>\|x\|, \quad \text { for any } x \in E \cap \partial \Omega_{R} .
$$

In view of (40) and (44), by Lemma 3, it follows that $T$ has a fixed point $x^{*} \in E \cap\left(\Omega_{R} \backslash \overline{\Omega_{r}}\right)$ with $r<\left\|x^{*}\right\|<R$, which is a positive $\omega$-periodic solution of (1). This proves Theorem 14 .

Corollary 15. Assume that $\left(H_{1}\right)-\left(H_{3}\right)$ and the following condition:

$$
\left(H_{13}\right) 1 / \alpha \sigma B^{\prime}(\xi) f_{\infty}<\lambda<1 / \beta B(\xi) f^{0}
$$

hold. Then (1) has a positive $\omega$-periodic solution. lary.

Similarly, we can prove the following theorem and corol-

Theorem 16. Assume that $\left(H_{1}\right)-\left(H_{4}\right)$ and the following conditions:

$$
\begin{aligned}
& \left(H_{14}\right) \beta\left(\lambda B(\xi) f^{\infty}+I^{\infty}\right)<1 \\
& \left(H_{15}\right) \alpha \sigma\left(\lambda B^{\prime}(\xi) f_{0}+I_{0}\right)>1
\end{aligned}
$$

hold. Then (1) has a positive $\omega$-periodic solution, where $f_{0}, f^{\infty}$, $I_{0}$, and $I^{\infty}$ are positive constants.

Corollary 17. Assume that $\left(H_{1}\right)-\left(H_{3}\right)$ and the following condition:

$$
\left(H_{16}\right) 1 / \alpha \sigma B^{\prime}(\xi) f_{0}<\lambda<1 / \beta B(\xi) f^{\infty}
$$

hold. Then (1) has a positive $\omega$-periodic solution.

Theorem 18. Assume that $\left(H_{1}\right)-\left(H_{4}\right),\left(H_{5}\right)$, and the following condition:

$$
\begin{gathered}
\left(H_{17}\right) 0<f^{0}<1 / 2 \lambda \beta B(\xi), 0<I^{0}<1 / 2 \beta \text { and } 0<f^{\infty}< \\
1 / 2 \lambda \beta B(\xi), 0<I^{\infty}<1 / 2 \beta,
\end{gathered}
$$

hold. Then (1) has two positive $\omega$-periodic solutions. 
Proof. First, we define $\Omega_{r}=\{x \in X:\|x\|<r\}$; then $\Omega_{r}$ is an open subset of $X$. From (7), $\left(H_{5}\right)$, and Lemma 4 , for any $x \in E \cap \partial \Omega_{r}$, we have

$$
\begin{aligned}
&\|(T x)(t)\|= \sum_{i=1}^{n}\left|T_{i} x\right|_{0} \\
&= \sum_{i=1}^{n}\left[\lambda \int_{t}^{t+\omega}\left|G_{i}(t, s) b_{i}(s, x(s)) f_{i}\left(s, x_{s}\right)\right| d s\right. \\
&\left.\quad+\sum_{t \leq t_{k}<t+\omega}\left|G_{i}\left(t, t_{k}\right) I_{k}^{i}\left(t_{k}, x\left(t_{k}\right)\right)\right|\right] \\
& \geq \lambda B^{\prime}(\xi) \sum_{i=1}^{n} \int_{t}^{t+\omega}\left|G_{i}(t, s) f_{i}\left(s, x_{s}\right)\right| d s \\
&+\sum_{i=1}^{n} \sum_{t \leq t_{k}<t+\omega}\left|G_{i}\left(t, t_{k}\right) I_{k}^{i}\left(t_{k}, x\left(t_{k}\right)\right)\right| \\
&= {\left[\lambda B^{\prime}(\xi) \int_{0}^{\omega}\left|f\left(s, x_{s}\right)\right| d s\right.} \\
&\left.\quad+\sum_{t \leq t_{k}<t+\omega}\left|I_{k}\left(t_{k}, x\left(t_{k}\right)\right)\right|\right] \\
& \geq \alpha\left(\lambda B^{\prime}(\xi) \underline{f}_{r}+\underline{I}_{r}\right)\|x\|>\|x\| .
\end{aligned}
$$

This yields

$$
\|(T x)(t)\|>\|x\|, \quad \text { for any } x \in E \cap \partial \Omega_{r} .
$$

On the one hand, since $0<f^{0}<1 / 2 \lambda \beta B(\xi)$ and $0<I^{0}<$ $1 / 2 \beta$, there exists $0<r_{1}<r$ such that for $0<\|x\|<r_{1}$

$$
\begin{gathered}
\int_{0}^{\omega}\left|f\left(t, x_{t}\right)\right| d t \leq \frac{r_{1}}{2 \lambda \beta B(\xi)} ; \\
\sum_{t \leq t_{k}<t+\omega}\left|I_{k}\left(t_{k}, x\left(t_{k}\right)\right)\right| \leq \frac{r_{1}}{2 \beta} .
\end{gathered}
$$

Set $\Omega_{r_{1}}=\left\{x \in X:\|x\|<r_{1}\right\}$; then $\Omega_{r_{1}}$ is an open subset of $X$. From (7), $\left(H_{17}\right)$, and Lemma 4 , for any $x \in E \cap \partial \Omega_{r_{1}}$, $t \in[0, \omega]$, and $1 \leq k<q$, we have

$$
\begin{aligned}
&(T x)(t)= \sum_{i=1}^{n}\left(T_{i} x\right) \\
&=\sum_{i=1}^{n}\left[\lambda \int_{t}^{t+\omega} G_{i}(t, s) b_{i}(s, x(s)) f_{i}\left(s, x_{s}\right) d s\right. \\
&\left.\quad+\sum_{t \leq t_{k}<t+\omega} G_{i}\left(t, t_{k}\right) I_{k}^{i}\left(t_{k}, x\left(t_{k}\right)\right)\right]
\end{aligned}
$$

$$
\begin{aligned}
& \leq \lambda B(\xi) \sum_{i=1}^{n} \int_{t}^{t+\omega}\left|G_{i}(t, s) f_{i}\left(s, x_{s}\right)\right| d s \\
& +\sum_{i=1}^{n} \sum_{t \leq t_{k}<t+\omega}\left|G_{i}\left(t, t_{k}\right) I_{k}^{i}\left(t_{k}, x\left(t_{k}\right)\right)\right| \\
& =\beta\left[\lambda B(\xi) \int_{0}^{\omega}\left|f\left(s, x_{s}\right)\right| d s\right. \\
& \left.\quad+\sum_{t \leq t_{k}<t+\omega}\left|I_{k}\left(t_{k}, x\left(t_{k}\right)\right)\right|\right] \\
& \leq \beta\left[\lambda B(\xi) \frac{1}{2 \lambda \beta B(\xi)}+\frac{r_{1}}{2 \beta}\right]\|x\|=\|x\| .
\end{aligned}
$$

This yields

$$
\|(T x)(t)\| \leq\|x\|, \quad \text { for any } x \in E \cap \partial \Omega_{r_{1}} .
$$

In view of (46) and (49), by Lemma 3 , it follows that $T$ has a fixed point $x_{1} \in E \cap\left(\Omega_{r} \backslash \overline{\Omega_{r 1}}\right)$ with $r_{1}<\left\|x_{1}\right\|<r$, which is a positive $\omega$-periodic solution of (1).

On the other hand, if $0<f^{\infty}<1 / 2 \lambda \beta B(\xi)$, and $0<I^{\infty}<$ $1 / 2 \beta$ hold, then there is $N>0$ such that

$$
\begin{gathered}
\int_{0}^{\omega}\left|f\left(t, x_{t}\right)\right| d t \leq \frac{N}{2 \lambda \beta B(\xi)} ; \\
\sum_{t \leq t_{k}<t+\omega}\left|I_{k}\left(t_{k}, x\left(t_{k}\right)\right)\right| \leq \frac{N}{2 \beta},
\end{gathered}
$$

for $x \geq N, t \in[0, \omega], 1 \leq k<q$. Let $r_{2}=\max \{2 r, N / \sigma\}$ and it follows that $x(t) \geq \sigma\|x\|>N$ for $x \in \Omega_{r_{2}}, t \in[0, \omega]$, and $0<k<q$. Thus

$$
\begin{gathered}
\int_{0}^{\omega}\left|f\left(t, x_{t}\right)\right| d t \leq \frac{1}{2 \lambda \beta B(\xi)}\|x\| ; \\
\sum_{t \leq t_{k}<t+\omega}\left|I_{k}\left(t_{k}, x\left(t_{k}\right)\right)\right| \leq \frac{1}{2 \beta}\|x\|,
\end{gathered}
$$

for $x \in \Omega_{r_{2}}, t \in[0, \omega], 1 \leq k<q$.

By $(7),\left(H_{17}\right)$, and Lemma 4 , we have

$$
\begin{aligned}
(T x)(t)= & \sum_{i=1}^{n}\left(T_{i} x\right) \\
=\sum_{i=1}^{n}\left[\lambda \int_{t}^{t+\omega} G_{i}(t, s) b_{i}(s, x(s)) f_{i}\left(s, x_{s}\right) d s\right. & \\
& \left.+\sum_{t \leq t_{k}<t+\omega} G_{i}\left(t, t_{k}\right) I_{k}^{i}\left(t_{k}, x\left(t_{k}\right)\right)\right]
\end{aligned}
$$




$$
\begin{aligned}
& \leq \lambda B(\xi) \sum_{i=1}^{n} \int_{t}^{t+\omega}\left|G_{i}(t, s) f_{i}\left(s, x_{s}\right)\right| d s \\
& +\sum_{i=1}^{n} \sum_{t \leq t_{k}<t+\omega}\left|G_{i}\left(t, t_{k}\right) I_{k}^{i}\left(t_{k}, x\left(t_{k}\right)\right)\right| \\
& =\beta\left[\lambda B(\xi) \int_{0}^{\omega}\left|f\left(s, x_{s}\right)\right| d s\right. \\
& \left.+\sum_{t \leq t_{k}<t+\omega}\left|I_{k}\left(t_{k}, x\left(t_{k}\right)\right)\right|\right] \\
& \leq \beta\left[\lambda B(\xi) \frac{1}{2 \lambda \beta B(\xi)}+\frac{r_{1}}{2 \beta}\right]\|x\|=\|x\| .
\end{aligned}
$$

This yields

$$
\|(T x)(t)\| \leq\|x\|, \quad \text { for any } x \in E \cap \partial \Omega_{r_{2}} \text {. }
$$

In view of (46) and (53), by Lemma 3, it follows that $T$ has a fixed point $x_{2} \in E \cap\left(\Omega_{r_{2}} \backslash \overline{\Omega_{r}}\right)$ with $r<\left\|x_{2}\right\|<r_{2}$, which is a positive $\omega$-periodic solution of (1). Therefore (1) has at least two positive periodic solutions; that is, $r_{1}<\left\|x_{1}\right\|<r<$ $\left\|x_{2}\right\|<r_{2}$. This proves Theorem 18 .

Remark 19. Assume that $\left(H_{1}\right)-\left(H_{4}\right),\left(H_{5}\right)$, and the following condition:

$$
\begin{gathered}
\left(H_{18}\right) 0<f^{0}<1 / 2 \lambda \beta B(\xi), 0<I^{0}<1 / 2 \beta \text { or } 0<f^{\infty}< \\
1 / 2 \lambda \beta B(\xi), 0<I^{\infty}<1 / 2 \beta
\end{gathered}
$$

hold. Then (1) has a positive $\omega$-periodic solution.

Corollary 20. Assume that $\left(H_{1}\right)-\left(H_{3}\right)$ and $\lambda>1 / \alpha \sigma B^{\prime}(\xi) f$ hold.

$\left(H_{17}\right)$ is satisfied; then (1) has two positive $\omega$-periodic solutions.

$\left(H_{18}\right)$ is satisfied; then (1) has a positive $\omega$-periodic solution.

From the arguments in the previous proof, we have the following consequences immediately.

Theorem 21. Assume that $\left(H_{1}\right)-\left(H_{4}\right),\left(H_{8}\right)$, and the following condition:

$$
\begin{aligned}
\left(H_{19}\right) \infty & >f_{0}>1 / 2 \lambda \alpha \sigma B^{\prime}(\xi), \infty>I_{0}>1 / 2 \alpha \sigma \text { and } \infty> \\
f_{\infty} & >1 / 2 \lambda \alpha \sigma B^{\prime}(\xi), \infty>I_{\infty}>1 / 2 \alpha \sigma
\end{aligned}
$$

hold. Then (1) has two positive $\omega$-periodic solutions.

Remark 22. Assume that $\left(H_{1}\right)-\left(H_{4}\right),\left(H_{8}\right)$, and the following condition:

$$
\begin{aligned}
\left(H_{20}\right) \infty & >f_{0}>1 / 2 \lambda \alpha \sigma B^{\prime}(\xi), \infty>I_{0}>1 / 2 \alpha \sigma \text { or } \infty> \\
f_{\infty} & >1 / 2 \lambda \alpha \sigma B^{\prime}(\xi), \infty>I_{\infty}>1 / 2 \alpha \sigma
\end{aligned}
$$

hold. Then (1) has a positive $\omega$-periodic solution.
Corollary 23. Assume that $\left(H_{1}\right)-\left(H_{3}\right)$ and $\lambda<1 / \beta B(\xi) \bar{f}_{r}$ hold.

$\left(H_{19}\right)$ is satisfied; then (1) has two positive w-periodic solutions.

$\left(H_{20}\right)$ is satisfied; then (1) has a positive w-periodic solution.

Theorem 24. Assume that $\left(H_{1}\right)-\left(H_{4}\right),\left(H_{5}\right)$, and one of the following conditions

$$
\begin{aligned}
& \left(H_{21}\right) f^{0}=I^{0}=0 \text { and } 0<f^{\infty}<1 / 2 \lambda \beta B(\xi), 0<I^{\infty}< \\
& 1 / 2 \beta, \\
& \left(H_{22}\right) \quad 0<f^{0}<1 / 2 \lambda \beta B(\xi), 0<I^{0}<1 / 2 \beta \text { and } f^{\infty}=I^{\infty}= \\
& 0
\end{aligned}
$$

hold. Then (1) has two positive $\omega$-periodic solutions.

Proof. We only consider the case $\left(H_{21}\right)$. When the case $\left(H_{22}\right)$ holds, the conclusion remains true by a similar proof and we will omit it. We define $\Omega_{r}=\{x \in X:\|x\|<r\}$; then $\Omega_{r}$ is an open subset of $X$. From (7), $\left(H_{5}\right)$, and Lemma 4 , for any $x \in E \cap \partial \Omega_{r}$, we have

$$
\begin{aligned}
\|(T x)(t)\|= & \sum_{i=1}^{n}\left|T_{i} x\right|_{0} \\
= & \sum_{i=1}^{n}\left[\lambda \int_{t}^{t+\omega}\left|G_{i}(t, s) b_{i}(s, x(s)) f_{i}\left(s, x_{s}\right)\right| d s\right. \\
& \left.+\sum_{t \leq t_{k}<t+\omega}\left|G_{i}\left(t, t_{k}\right) I_{k}^{i}\left(t_{k}, x\left(t_{k}\right)\right)\right|\right] \\
\geq & \lambda B^{\prime}(\xi) \sum_{i=1}^{n} \int_{t}^{t+\omega}\left|G_{i}(t, s) f_{i}\left(s, x_{s}\right)\right| d s \\
& +\sum_{i=1}^{n} \sum_{t \leq t_{k}<t+\omega}\left|G_{i}\left(t, t_{k}\right) I_{k}^{i}\left(t_{k}, x\left(t_{k}\right)\right)\right| \\
= & {\left[\lambda B^{\prime}(\xi) \int_{0}^{\omega}\left|f\left(s, x_{s}\right)\right| d s\right.} \\
& \left.+\sum_{t \leq t_{k}<t+\omega}\left|I_{k}\left(t_{k}, x\left(t_{k}\right)\right)\right|\right] \\
& \left(\lambda B^{\prime}(\xi) \underline{f}_{r}+\underline{I}_{r}\right)\|x\|>\|x\| .
\end{aligned}
$$

This yields

$$
\|(T x)(t)\|>\|x\|, \quad \text { for any } x \in E \cap \partial \Omega_{r} .
$$

On the one hand, if $f^{0}=I^{0}=0$ holds, then we can choose $0<r_{1}<r$, such that $\int_{0}^{\omega}\left|f\left(t, x_{t}\right)\right| d t \leq \epsilon\|x\|$ and $\sum_{t \leq t_{k}<t+\omega}\left|I_{k}\left(t_{k}, x\left(t_{k}\right)\right)\right| \leq \epsilon\|x\|$ for $x \in\left[0, r_{1}\right], t \in[0, \omega]$, and 
$1 \leq k<q$, where constant $\epsilon>0$ satisfies $\epsilon \beta(\lambda B(\xi)+1) \leq 1$. By $(7),\left(H_{21}\right)$, and Lemma 4 , we can obtain

$$
\begin{aligned}
(T x)(t)= & \sum_{i=1}^{n}\left(T_{i} x\right) \\
= & \sum_{i=1}^{n}\left[\lambda \int_{t}^{t+\omega} G_{i}(t, s) b_{i}(s, x(s)) f_{i}\left(s, x_{s}\right) d s\right. \\
& \left.\quad+\sum_{t \leq t_{k}<t+\omega} G_{i}\left(t, t_{k}\right) I_{k}^{i}\left(t_{k}, x\left(t_{k}\right)\right)\right] \\
\leq & \lambda B(\xi) \sum_{i=1}^{n} \int_{t}^{t+\omega}\left|G_{i}(t, s) f_{i}\left(s, x_{s}\right)\right| d s \\
& +\sum_{i=1}^{n} \sum_{t \leq t_{k}<t+\omega}\left|G_{i}\left(t, t_{k}\right) I_{k}^{i}\left(t_{k}, x\left(t_{k}\right)\right)\right| \\
= & \beta\left[\lambda B(\xi) \int_{0}^{\omega}\left|f\left(s, x_{s}\right)\right| d s\right. \\
& \left.\quad+\sum_{t \leq t_{k}<t+\omega}\left|I_{k}\left(t_{k}, x\left(t_{k}\right)\right)\right|\right] \\
\leq & \epsilon \beta(\lambda B(\xi)+1)\|x\| \leq\|x\| .
\end{aligned}
$$

This yields

$$
\|(T x)(t)\| \leq\|x\|, \quad \text { for any } x \in E \cap \partial \Omega_{r_{1}} .
$$

In view of (55) and (57), by Lemma 3 , it follows that $T$ has a fixed point $x_{1} \in E \cap\left(\Omega_{r} \backslash \overline{\Omega_{r 1}}\right)$ with $r_{1}<\left\|x_{1}\right\|<r$, which is a positive $\omega$-periodic solution of (1).

On the other hand, if $0<f^{\infty}<1 / 2 \lambda \beta B(\xi)$ and $0<I^{\infty}<$ $1 / 2 \beta$ hold, then there is $N>0$ such that

$$
\begin{gathered}
\int_{0}^{\omega}\left|f\left(t, x_{t}\right)\right| d t \leq \frac{N}{2 \lambda \beta B(\xi)} \\
\sum_{t \leq t_{k}<t+\omega}\left|I_{k}\left(t_{k}, x\left(t_{k}\right)\right)\right| \leq \frac{N}{2 \beta},
\end{gathered}
$$

for $x \geq N, t \in[0, \omega]$, and $1 \leq k<q$; let $r_{2}=\max \{2 r, N / \sigma\}$ and it follows that $x(t) \geq \sigma\|x\|>N$ for $x \in \Omega_{r_{2}}, t \in[0, \omega]$, and $0<k<q$. Thus

$$
\begin{gathered}
\int_{0}^{\omega}\left|f\left(t, x_{t}\right)\right| d t \leq \frac{1}{2 \lambda \beta B(\xi)}\|x\| ; \\
\sum_{t \leq t_{k}<t+\omega}\left|I_{k}\left(t_{k}, x\left(t_{k}\right)\right)\right| \leq \frac{1}{2 \beta}\|x\|,
\end{gathered}
$$

$$
\text { for } x \in \Omega_{r_{2}}, \quad t \in[0, \omega], 1 \leq k<q \text {. }
$$

By $(7),\left(H_{21}\right)$, and Lemma 4 , we have

$$
\begin{aligned}
(T x)(t)= & \sum_{i=1}^{n}\left(T_{i} x\right) \\
= & \sum_{i=1}^{n}\left[\lambda \int_{t}^{t+\omega} G_{i}(t, s) b_{i}(s, x(s)) f_{i}\left(s, x_{s}\right) d s\right. \\
& \left.\quad+\sum_{t \leq t_{k}<t+\omega} G_{i}\left(t, t_{k}\right) I_{k}^{i}\left(t_{k}, x\left(t_{k}\right)\right)\right] \\
\leq & \lambda B(\xi) \sum_{i=1}^{n} \int_{t}^{t+\omega}\left|G_{i}(t, s) f_{i}\left(s, x_{s}\right)\right| d s \\
& +\sum_{i=1}^{n} \sum_{t \leq t_{k}<t+\omega}\left|G_{i}\left(t, t_{k}\right) I_{k}^{i}\left(t_{k}, x\left(t_{k}\right)\right)\right| \\
= & {\left[\quad \lambda B(\xi) \int_{0}^{\omega}\left|f\left(s, x_{s}\right)\right| d s\right.} \\
& \left.\quad+\sum_{t \leq t_{k}<t+\omega}\left|I_{k}\left(t_{k}, x\left(t_{k}\right)\right)\right|\right] \\
\leq & \beta\left[\lambda B(\xi) \frac{1}{2 \lambda \beta B(\xi)}+\frac{r_{1}}{2 \beta}\right]\|x\|=\|x\| .
\end{aligned}
$$

This yields

$$
\|(T x)(t)\| \leq\|x\|, \quad \text { for any } x \in E \cap \partial \Omega_{r_{2}} .
$$

In view of (55) and (61), by Lemma 3 , it follows that $T$ has a fixed point $x_{2} \in E \cap\left(\Omega_{r_{2}} \backslash \overline{\Omega_{r}}\right)$ with $r<\left\|x_{2}\right\|<r_{2}$, which is a positive $\omega$-periodic solution of (1). Therefore (1) has at least two positive periodic solutions; that is, $r_{1}<\left\|x_{1}\right\|<r<$ $\left\|x_{2}\right\|<r_{2}$. This proves Theorem 24.

Remark 25. Assume that $\left(H_{1}\right)-\left(H_{4}\right),\left(H_{5}\right)$, and one of the following conditions:

$$
\begin{aligned}
& \left(H_{23}\right) f^{0}=I^{0}=0 \text { or } 0<f^{\infty}<1 / 2 \lambda \beta B(\xi), 0<I^{\infty}<1 / 2 \beta, \\
& \left(H_{24}\right) 0<f^{0}<1 / 2 \lambda \beta B(\xi), 0<I^{0}<1 / 2 \beta \text { or } f^{\infty}=I^{\infty}=0
\end{aligned}
$$

hold. Then (1) has a positive $\omega$-periodic solution.

Corollary 26. Assume that $\left(H_{1}\right)-\left(H_{3}\right)$ and $\lambda>1 / \alpha \sigma B^{\prime}(\xi) \underline{f}_{r}$ hold.

Either $\left(H_{21}\right)$ or $\left(H_{22}\right)$ is satisfied; then (1) has two positive $\omega$-periodic solutions.

Either $\left(H_{23}\right)$ or $\left(H_{24}\right)$ is satisfied; then (1) has a positive $\omega$-periodic solution.

From the arguments in the previous proof, we have the following consequences immediately.

Theorem 27. Assume that $\left(H_{1}\right)-\left(H_{4}\right),\left(H_{8}\right)$, and one of the following conditions: 


$$
\begin{aligned}
& \left(H_{25}\right) f_{0}=I_{0}=0 \text { and } \infty>f_{\infty}>1 / 2 \lambda \alpha \sigma B^{\prime}(\xi), \infty>I_{\infty}> \\
& 1 / 2 \alpha \sigma, \\
& \left(H_{26}\right) \infty>f_{0}>1 / 2 \lambda \alpha \sigma B^{\prime}(\xi), \infty>I_{0}>1 / 2 \alpha \sigma \text { and } f_{\infty}= \\
& I_{\infty}=0
\end{aligned}
$$

hold. Then (1) has two positive $\omega$-periodic solutions.

Remark 28. Assume that $\left(H_{1}\right)-\left(H_{4}\right),\left(H_{8}\right)$, and one of the following conditions

$$
\begin{aligned}
& \left(H_{27}\right) f_{0}=I_{0}=0 \text { or } \infty>f_{\infty}>1 / 2 \lambda \alpha \sigma B^{\prime}(\xi), \infty>I_{\infty}> \\
& \left(H_{28}\right) \infty>f_{0}>1 / 2 \lambda \alpha \sigma B^{\prime}(\xi), \infty>I_{0}>1 / 2 \alpha \sigma \text { or } f_{\infty}= \\
& I_{\infty}=0
\end{aligned}
$$

hold. Then (1) has a positive $\omega$-periodic solution.

Corollary 29. Assume that $\left(H_{1}\right)-\left(H_{3}\right)$ and $\lambda<1 / \beta B(\xi) \bar{f}_{r}$ hold.

Either $\left(\mathrm{H}_{25}\right)$ or $\left(\mathrm{H}_{26}\right)$ is satisfied; then (1) has two positive $\omega$-periodic solutions.

Either $\left(H_{27}\right)$ or $\left(H_{28}\right)$ is satisfied; then (1) has a positive $\omega$-periodic solution.

Remark 30. Suppose that $B(t, x(t))=1$ and $I_{k}\left(t_{k}, x\left(t_{k}\right)\right)=$ 0 , under some conditions; we can obtain the corresponding results of [17]. Hence, our results generalize and improve the corresponding results of [17].

Remark 31. Assume that $A(t, x(t))=A(t), B(t, x(t))=1, \lambda=$ 1 under some conditions; we can obtain the corresponding results of [18]. Hence, our results generalize and improve the corresponding results of [18].

\section{Conflict of Interests}

The author declares that there is no conflict of interests regarding the publication of this paper.

\section{Acknowledgments}

This research is supported by NSF of China (nos. 11161015, 11371367, and 11361012), PSF of China (nos. 2012M512162 and 2013T60934), NSF of Hunan Province (nos. 11JJ900, 12JJ9001, and 13JJ4098), the Science Foundation of Hengyang Normal University (no. 11B36), and the Construct Program of the Key Discipline in Hunan Province.

\section{References}

[1] D. Y. Xu and Z. C. Yang, "Impulsive delay differential inequality and stability of neural networks," Journal of Mathematical Analysis and Applications, vol. 305, no. 1, pp. 107-120, 2005.

[2] A. M. Zhao and J. R. Yan, "Asymptotic behavior of solutions of impulsive delay differential equations," Journal of Mathematical Analysis and Applications, vol. 201, no. 3, pp. 943-954, 1996.

[3] Y. P. Xing and M. A. Han, "A new approach to stability of impulsive functional differential equations," Applied Mathematics and Computation, vol. 151, no. 3, pp. 835-847, 2004.
[4] Z. G. Luo and L. P. Luo, "Global positive periodic solutions of generalized $n$-species competition systems with multiple delays and impulses," Abstract and Applied Analysis, vol. 2013, Article ID 980974, 12 pages, 2013.

[5] W. T. Li and H. F. Huo, "Existence and global attractivity of positive periodic solutions of functional differential equations with impulses," Nonlinear Analysis: Theory, Methods \& Applications, vol. 59, no. 6, pp. 857-877, 2004.

[6] J. S. Yu, "Stability for nonlinear delay differential equations of unstable type under impulsive perturbations," Applied Mathematics Letters, vol. 14, no. 7, pp. 849-857, 2001.

[7] X. Y. Li, X. N. Lin, D. Q. Jiang, and X. Y. Zhang, "Existence and multiplicity of positive periodic solutions to functional differential equations with impulse effects," Nonlinear Analysis: Theory, Methods \& Applications, vol. 62, no. 4, pp. 683-701, 2005.

[8] G. Ballinger and X. Z. Liu, "Existence, uniqueness and boundedness results for impulsive delay differential equations," Applicable Analysis, vol. 74, no. 1-2, pp. 71-93, 2000.

[9] J. R. Yan, "Global attractivity for impulsive population dynamics with delay arguments," Nonlinear Analysis: Theory, Methods \& Applications, vol. 71, no. 11, pp. 5417-5426, 2009.

[10] M. Liu and K. Wang, "Asymptotic behavior of a stochastic nonautonomous Lotka-Volterra competitive system with impulsive perturbations," Mathematical and Computer Modelling, vol. 57, no. 3-4, pp. 909-925, 2013.

[11] A. M. Samoikleno and N. A. Perestyuk, Impulsive Differential Equations, World Scientific, Singapore, 1995.

[12] Z. G. Luo, B. X. Dai, and Q. H. Zhang, "Existence of positive periodic solutions for an impulsive semi-ratio-dependent predator-prey model with dispersion and time delays," Applied Mathematics and Computation, vol. 215, no. 9, pp. 3390-3398, 2010.

[13] X. Q. Ding, C. W. Wang, and P. Chen, "Permanence for a twospecies Gause-type ratio-dependent predator-prey system with time delay in a two-patch environment," Applied Mathematics and Computation, vol. 219, no. 17, pp. 9099-9105, 2013.

[14] Y. F. Shao and B. X. Dai, "The dynamics of an impulsive delay predator-prey model with stage structure and Beddington-type functional response," Nonlinear Analysis: Real World Applications, vol. 11, no. 5, pp. 3567-3576, 2010.

[15] X. D. Li and X. L. Fu, "On the global exponential stability of impulsive functional differential equations with infinite delays or finite delays," Communications in Nonlinear Science and Numerical Simulation, vol. 19, no. 3, pp. 442-447, 2014.

[16] Z. G. Luo, L. P. Luo, and Y. H. Zeng, "Positive periodic solutions for impulsive functional differential equations with infinite delay and two parameters," Journal of Applied Mathematics, vol. 2014, Article ID 751612, 17 pages, 2014.

[17] Z. J. Zeng, B. Li, and M. Fan, "Existence of multiple positive periodic solutions for functional differential equations," Journal of Mathematical Analysis and Applications, vol. 325, no. 2, pp. 1378-1389, 2007.

[18] N. Zhang, B. X. Dai, and X. Z. Qian, "Periodic solutions for a class of higher-dimension functional differential equations with impulses," Nonlinear Analysis: Theory, Methods \& Applications, vol. 68, no. 3, pp. 629-638, 2008.

[19] D. Q. Jiang, D. O’Regan, R. P. Agarwal, and X. J. Xu, “On the number of positive periodic solutions of functional differential equations and population models," Mathematical Models \& Methods in Applied Sciences, vol. 15, no. 4, pp. 555-573, 2005.

[20] D. J. Guo, Nonlinear Functional Analysis, Shandong Science and Technology Press, Shandong, China, 2001, (in Chinese). 
[21] V. Lakshmikantham, D. D. Bainnov, and P. S. Simeonov, Theory of Impulsive Differential Equations, World Scientific, Singapore, 1989.

[22] M. A. Krasnoselskii, Positive Solution of Operator Equation, Noordhoff, Gröningen, The Netherlands, 1964.

[23] K. Deimling, Nonlinear Functional Analysis, Springer, Berlin, Germany, 1985.

[24] D. Guo and V. Lakshmikantham, Nonlinear Problems in Abstract Cones, vol. 5, Academic Press, Orlando, Fla, USA, 1988.

[25] Y. H. Fan, W. T. Li, and L. L. Wang, "Periodic solutions of delayed ratio-dependent predator-prey models with monotonic or nonmonotonic functional responses," Nonlinear Analysis: Real World Applications, vol. 5, no. 2, pp. 247-263, 2004. 


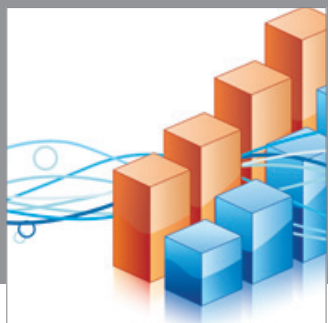

Advances in

Operations Research

mansans

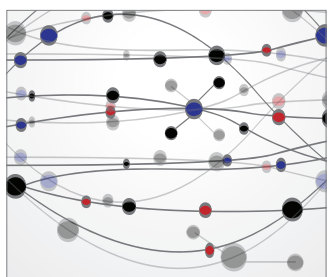

The Scientific World Journal
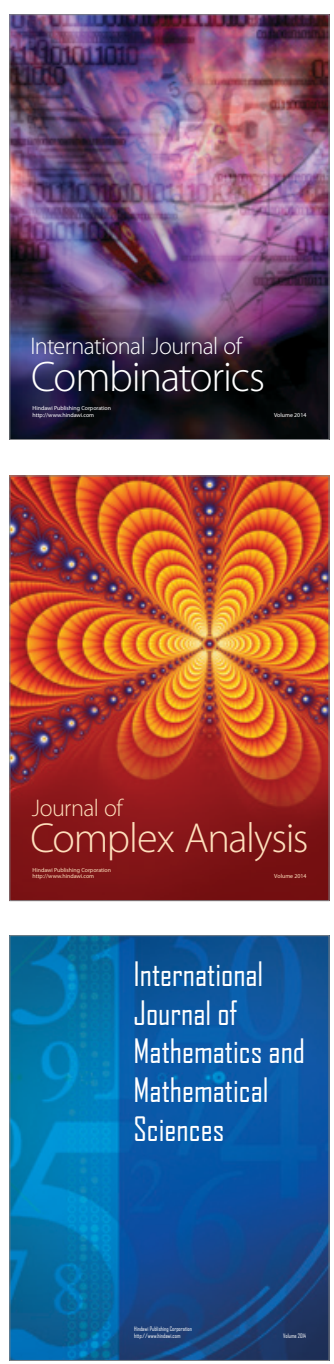
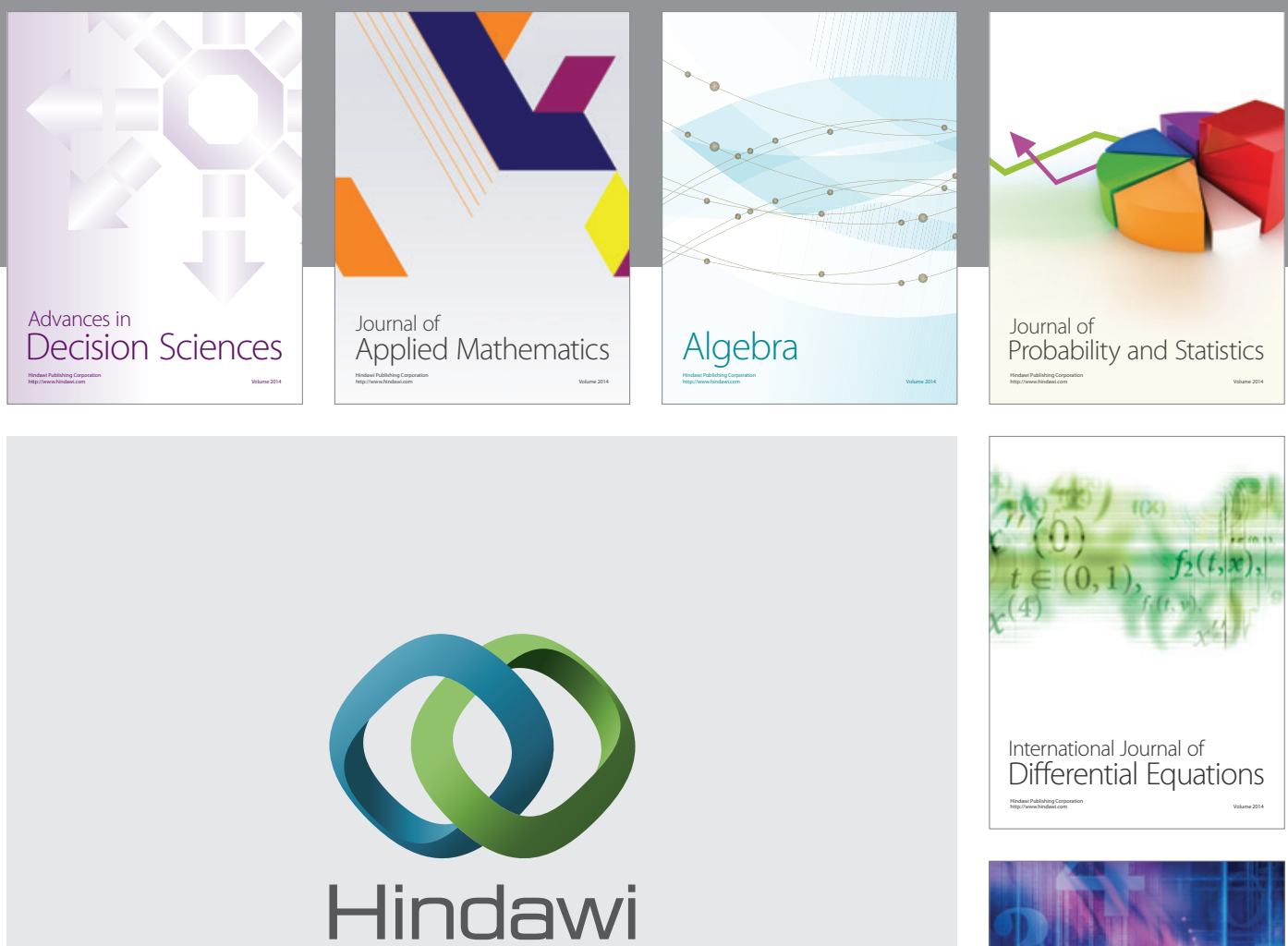

Submit your manuscripts at http://www.hindawi.com
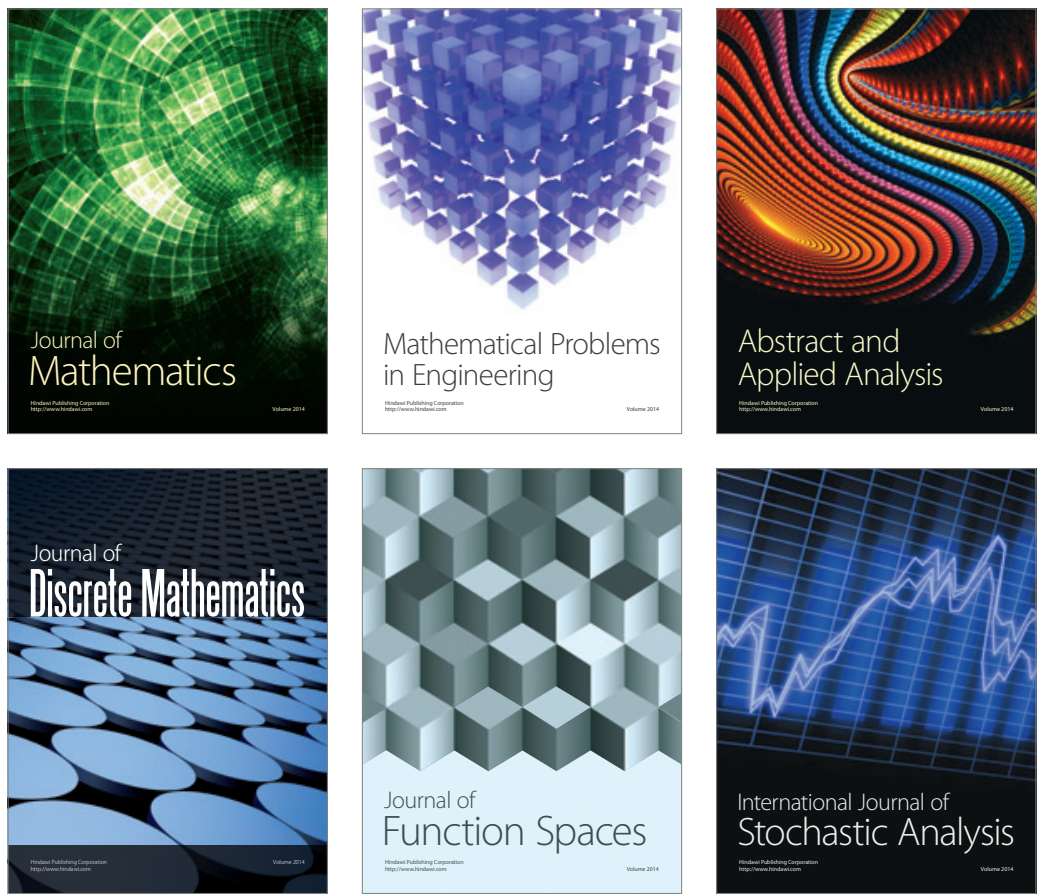

Journal of

Function Spaces

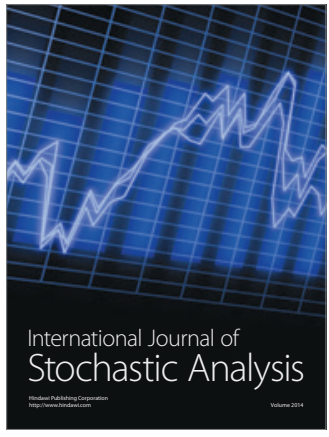

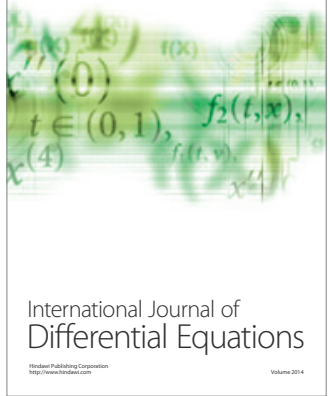
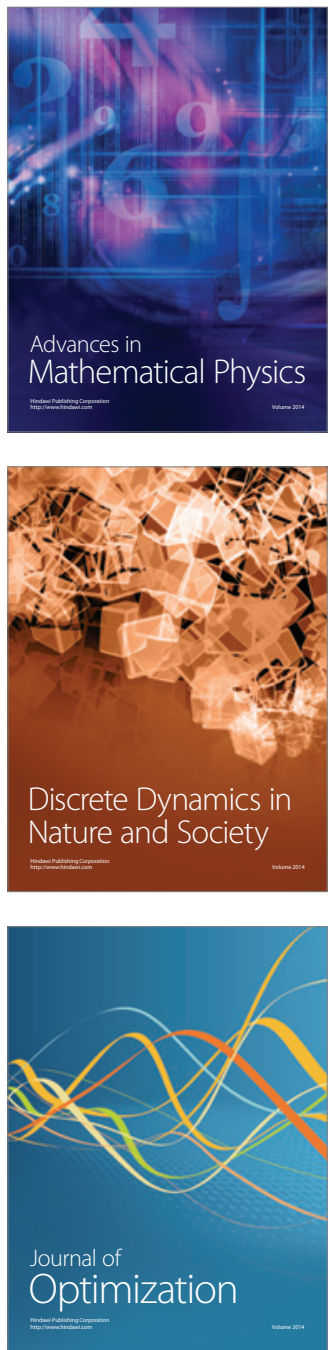